\title{
Validation of Multivariate Calibration Models in the Determination of Sugar Cane Quality Parameters by Near Infrared Spectroscopy
}

\author{
Patrícia Valderrama, Jez W. B. Braga and Ronei J. Poppi*
}

Instituto de Química, Universidade Estadual de Campinas, CP 6154, 13084-862 Campinas-SP, Brazil

\begin{abstract}
Os teores de sólidos solúveis (BRIX), açúcares polarizáveis (POL) e açúcares redutores (RS) em caldo de cana foram determinados utilizando espectroscopia na região do infravermelho próximo (NIR) e calibração multivariada, a qual foi validada pelo cálculo das figuras de mérito. Devido à heterogeneidade das amostras, foi necessário, como primeira etapa do trabalho, a otimização dos conjutos de calibração e validação através da eliminação das amostras anômalas (outliers). As figuras de mérito como: sensibilidade, sensibilidade analítica, seletividade, limites de confiança, precisão (média, repetibilidade), exatidão e razão sinal-ruído foram calculadas. Resultados viáveis foram obtidos para BRIX e POL apresentando resultados de RMSEP de 0,28 e $0,42 \%$ de caldo, respectivamente. Os coeficientes de correlação para ambos os parâmetros foram de 0,99. Estes resultados indicam que os modelos desenvolvidos para BRIX e POL podem ser seguramente utilizados como uma alternativa em relação ao método padrão utilizado na indústria alcooleira.
\end{abstract}

The determination of soluble solids (BRIX), polarizable sugars (POL) and reducing sugars (RS) sugar cane juice by using near infrared spectroscopy (NIR) and multivariate calibration was developed and validated by calculation of figures of merit. Due to the heterogeneity of the samples, first it was necessary to optimize the calibration set by outlier elimination. The figures of merit such as: sensitivity, analytical sensitivity, selectivity, confidence limit, precision (mean, repeatability), accuracy and signal-to-noise ratio were calculated. Feasible results were obtained for BRIX and POL with RMSEP values of 0.28 and $0.42 \%$ of juice and precision of 0.02 and $0.08 \%$ of juice, respectively. For both BRIX and POL goodness of fit showed correlation coefficients of 0.99 . These results indicate that the models developed for BRIX and POL can be used as an alternative to standard procedures in the sugar cane industry.

Keywords: sugar cane, multivariate calibration, net analyte signal, figures of merit

\section{Introduction}

Nowadays, the industrial production of alcohol (ethanol) in Brazil has become a strategic area due its applicability as an alternative fuel, since sugar cane is the basic raw material for its manufacture. ${ }^{1}$ The sugars of cane are basically represented by sucrose, glucose and fructose. Sucrose $\left(\mathrm{C}_{12} \mathrm{H}_{22} \mathrm{O}_{11}\right)$ is a disaccharide which constitutes the principal parameter of quality of sugar cane and under acid conditions, or action of enzymes, is unfolded to its monosaccharide molecules, which causes a decrease in alcohol production. Glucose and fructose are also called reducing sugars, because they have the property of reducing copper from the $\mathrm{Cu}^{2+}$ state to $\mathrm{Cu}^{1+} .{ }^{2,3}$ In the calculation of sugar cane costs by industry, the main

*e-mail: ronei@iqm.unicamp.br parameter used is the cane quality, estimated according to its concentration in recoverable total sugar (RTS), which is function of polarizable sugar (POL), soluble solids (BRIX) and reducing sugars (RS). ${ }^{3,4}$ The parameters mentioned above are estimated by measurement with saccharimeters, densimeters and oxidation-reduction titrations, respectively, as standard methodologies, that are regulated by norms of evaluation of the quality of sugar cane.

BRIX can be defined as the percentage in weight, or in volume, of soluble solids expressed as sucrose. In sugar cane juice it is a quantitative measurement of the total solids (including sugars), not giving any qualitative information about which sugars are present in the final product. ${ }^{3}$ POL is a measurement of the amount of sucrose in the mixture of sugars, because in it, only sucrose diverts the plane of polarized light. ${ }^{4} \mathrm{RS}$ can be evaluated by 
oxidation-reduction titration. However, for sugar cane grower payment, RS is not determined via analysis, but is just estimated by an equation that takes in consideration the BRIX and POL parameters. ${ }^{3}$

Alternative methods of analysis for sugar cane grower payment, such as mid infrared spectroscopy and fluorescence, have been investigated and tested, with the aim to increase the reliability, uniformity of the method and the accuracy of the measurements. ${ }^{5,7}$ Near infrared spectroscopy (NIR) has been recently investigated as an alternative methodology, due its special characteristics such as non-destructivity, quickness and no production of offensive wastes..$^{8-13}$ Nowadays, some distilleries in Brazil have began the implementation of this analytical methodology. In this case, the application of NIR should be validated using an independent data set and by calculation of figures of merit to certify its ability to predict the properties of interest. However, based on the reference norm ${ }^{3}$ actually employed, figures of merit are not calculated.

The aims of this work were built and validate multivariate calibration models for determination of BRIX, POL and RS using the near infrared spectra of cane juice. For this purpose, figures of merit such as: sensitivity, analytical sensitivity, selectivity, confidence limit, precision (mean, repeatability), accuracy and signalto-noise ratio were calculated, and the model results were compared with reference values obtained by the standard methods to confirm the applicability of the proposed methodology.

\section{Experimental}

The experimental measurements of this work were accomplished at alcohol plant Cocamar - Cooperativa Agroindustrial, located at São Tomé city in the State of Paraná - Brazil.

Ripe cane sugar arrives in the industry transported by trucks and were sampled by horizontal probe. Samples were cut and carried to the laboratory. In the laboratory, the samples were pressed to $250 \mathrm{kgf} \mathrm{cm}^{-2}$ in an hydraulic press for a period of 1 minute, resulting in the cane juice for subsequent analysis. Finally, before the spectra acquisition, the samples were filtered in cotton to eliminate suspended particles.

Spectra were collected at a NIRSystems spectrometer, model 5000 monochromator, equipped with a tungsten filament source, quartz cuvette of $1 \mathrm{~mm}$ of optical path and a $\mathrm{PbS}$ detector. Acquisition of the spectra was accomplished in the range of $1100-2500 \mathrm{~nm}$ by using the ISIScan software.
A total of 1381 samples of sugar cane juice were used in this work. Each sample was submitted to conventional analysis and the results were used as reference values for model development.

The BRIX values were obtained directly, using a digital densimeter with a precision of $0.01{ }^{\circ}$ BRIX. The POL measurements were obtained in a digital saccharimeter with precision of 0.01 . The samples of cane juice were initially cleared with lead sub-acetate $\left(\mathrm{Pb}\left(\mathrm{CH}_{3} \mathrm{COO}\right)_{2} \cdot \mathrm{Pb}(\mathrm{OH})_{2}\right)$ and filtered before the measurements. The degree of polarization of the sample, expressed as \% of juice, was calculated based on the saccharimeter reading (SR) and equation 1.

$\mathrm{POL}=\mathrm{SR}(0.2605-0.0009882 \mathrm{BRIX})$

In RS determination, the standard methodology used was proposed by Eynon \& Lane, which consists in the oxidation-reduction titration of the Fehling Liqueur by the filtered cane juice. RS (also expressed as \% of juice) present in each sample was obtained by equation 2 , taking into consideration the standard volume spent in the titration of the Felhling Liqueur solution by a solution of $1 \%$ of inverted sugar and the BRIX measurement. ${ }^{3}$

$\mathrm{RS}=\frac{\left[\frac{5.2096-\left(1.74993 \mathrm{SR} \frac{\mathrm{VS}}{\mathrm{Vs}}\right)}{500}\right]}{\left.25.64 \frac{\mathrm{VS}}{\mathrm{Vs}}(0.00398 \mathrm{BRIX}+0.99692)\right)}$

where VS is the volume of cane juice spent in the titration and Vs is the standard volume of the inverted sugar.

Figure 1 shows the spectra of all 1381 samples. These samples, for calculations purposes, were split in 1003 calibration samples and 378 validation ones, by using the Kennard-Stone algorithm. ${ }^{14}$ The intense band in the region around $1900 \mathrm{~nm}$ was eliminated due the high water absorption $^{15}$ and mean centering was used for data preprocessing. Calibrations models were developed using the PLS-Toolbox version 3.5 from Eigen_Vector Technology for Matlab 6.5, based on PLS1 method. The validation was accomplished by the calculation of figures of merit using Matlab routines developed in our laboratory.

\section{Theory}

The data matrix $\mathbf{X}$ is formed by the NIR spectra of the sugar cane juice and the vector $\mathbf{y}$ contains the reference values for each property of interest. One PLS model for each property was built and the net analyte signal (NAS) was calculated. 


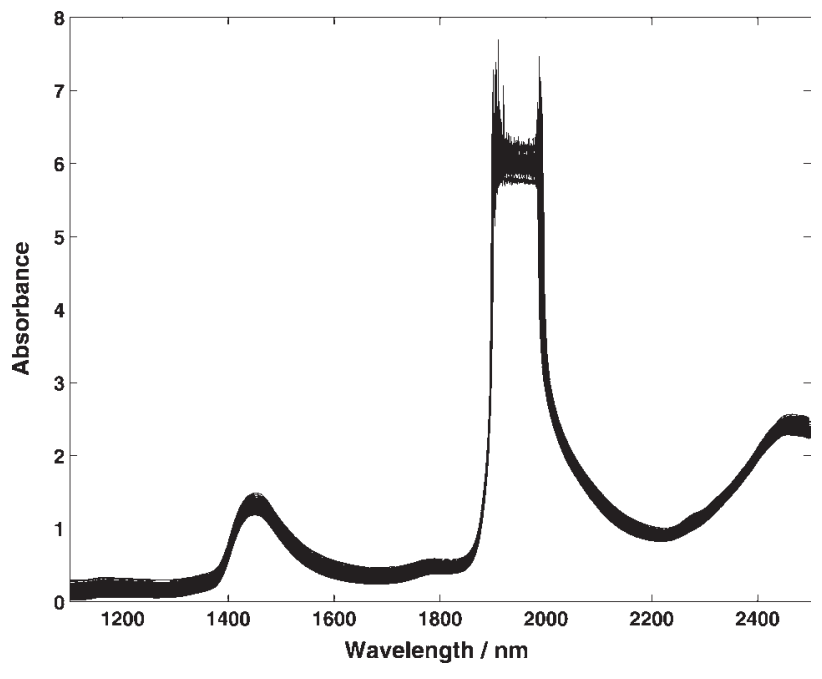

Figure 1. NIR spectra of sugar cane juice.

For the calculation of the NAS, the matrix $\mathbf{X}$ is rebuilt based on $A$ latent variables calculated by PLS, yielding the matrix $\hat{\mathbf{X}}_{\mathrm{A}}$. Subsequently, the matrix free from the contribution of the analyte of interest $\mathrm{k}\left(\hat{\mathbf{X}}_{\mathrm{A},-\mathrm{k}}\right)$ is calculated as: ${ }^{16}$

$\hat{\mathbf{X}}_{\mathrm{A},-\mathrm{k}}=\left[\mathrm{I}-\hat{\mathbf{y}}_{\mathrm{A}, \mathrm{k}} \hat{\mathbf{y}}_{\mathrm{A}, \mathrm{k}}^{+}\right] \hat{\mathbf{X}}_{\mathrm{A}}$

where $\hat{\mathbf{y}}_{\mathrm{A}, \mathbf{k}}$ is the concentration vector $\mathbf{y}_{\mathrm{k}}$ projected down onto the A-dimensional space calculated by PLS and the '+' superscript is the Moore-Penrose pseudoinverse.

The NAS vector for the 'i' calibration or validation sample $\hat{\mathbf{x}}_{\mathrm{A}, \mathrm{k}, \mathrm{i}}^{\text {nas }}$ can be written as:

$\hat{\mathbf{X}}_{\mathrm{A}, \mathrm{k}, \mathrm{i}}^{\mathrm{nas}}=\left(\mathbf{I}-\hat{\mathbf{X}}_{\mathrm{A},-\mathbf{k}}^{\top}\left(\hat{\mathbf{X}}_{\mathrm{A},-\mathrm{k}}^{\top}\right)^{+}\right) \hat{\mathbf{X}}_{\mathrm{A}, \mathrm{k}, \mathrm{i}}^{\top}$

where $\mathbf{I}$ is the identity matrix of appropriate size and $\hat{\mathbf{x}}_{\mathrm{A}, \mathrm{k}, \mathrm{i}}$ is the NAS vector. It is important to note that $\hat{\mathbf{x}}_{\mathrm{A}, \mathrm{k}, \mathrm{i}}$ contains only the information of analyte k (BRIX, POL or RS), thus it is possible to replace it by its Euclidean norm, generating a scalar nas:

nâs $_{\mathrm{i}, \mathrm{k}}=\left\|\hat{\mathbf{x}}_{\mathrm{A}, \mathrm{k}, \mathrm{i}}^{\text {nas }}\right\|$

Since the experimental responses of analyte $\mathrm{k}$ can be expressed as a scalar value, an univariate inverse calibration model can be built by the least squares method as:

$\hat{\mathrm{b}}_{\mathrm{nas}, \mathrm{k}}=\left(\text { nâs }_{\mathrm{cal}, \mathrm{k}}^{\top} \text { nâs }_{\mathrm{cal}, \mathrm{k}}\right)^{-1} \mathrm{nâs}_{\mathrm{cal}, \mathrm{k}}^{\top} \mathbf{y}_{\mathrm{cal}, \mathrm{k}}$

where nâs cal.k $_{\text {and }} \mathbf{y}_{\text {cal.k }}$ are the NAS and the reference values for the calibration samples and $\hat{b}_{\text {nas, } \mathrm{k}}$ is the regression coefficient of the pseudo univariate model. If the data matrix was meancentered, before of the determination of $\hat{b}_{\text {nas, } \mathrm{k}}$, the nâs $s_{\mathrm{i}, \mathrm{k}}$ needs to be changed to avoid a signal error that is inserted by implementation of the Euclidean norm. This correction can be performed by multiplication of the nâs $s_{i, k}$ by the signal of $\left(\mathrm{y}_{\mathrm{i}}-\overline{\mathrm{y}}_{\mathrm{cal}}\right)$, where $\overline{\mathrm{y}}_{\mathrm{cal}}$ is the respective analyte concentration average of the calibration samples. ${ }^{17}$ The pseudo-univariate model represents faithful the multivariate model in a simple form that can be presented as an usual analytical curve.

\section{Analytical figures of merit}

Accuracy reports the closeness of agreement between the reference value and the value found by the calibration model. In Chemometrics, this is generally expressed as the root mean square error of the prediction samples (RMSEP), that is an approximation of the standard error of the prediction samples, obtained as: ${ }^{18}$

RMSEP $=\sqrt{\frac{\sum_{i=1}^{n}\left(y_{i}-\hat{y}_{i}\right)^{2}}{n}}$

where $\mathrm{n}$ is the number of prediction samples. The accuracy expressed by equation 7 assumes that the error in the reference values is neglected. In applications where this assumption can not be made this error should be taking count, as is discussed by Faber and Kowalski. ${ }^{19}$

Precision represents the degree of scatter between a series of measurements for the same sample under prescribed conditions. It is usually expressed as a standard deviation, or relative standard deviation, of a series of measurements. ${ }^{20}$

precision $=\sqrt{\frac{\sum_{i=1}^{n} \sum_{j=1}^{m}\left(\hat{y}_{i, j}-\hat{\bar{y}}_{i}\right)^{2}}{n(m-1)}}$

where $\mathrm{n}$ is the number of samples and $\mathrm{m}$ the number of replicates. In agreement with $\mathrm{ASTM}^{20}$ it should be determined as the mean of the standard deviation of a minimum of six measurements on a minimum of three samples.

Signal-to-Noise Ratio in the univariate case this parameter represents how much the signal of the analyte $\mathrm{k}$ is larger than the instrumental noise. In the present case, this is calculated as: $:^{21}$

$\mathrm{S} / \mathrm{N}_{\mathrm{k}, \mathrm{i}}=\frac{\mathrm{nâs}_{\mathrm{k}, \mathrm{i}}}{\delta \mathrm{x}}$

where $\delta \mathrm{x}$ is an estimate for the instrumental noise, calculated as the standard deviation of 15 blank samples. 
Sensitivity this parameter informs what fraction of analytical signal that is due to the increase of the concentration of a particular analyte at unitary concentration. In inverse multivariate calibration models, it is defined as: ${ }^{21,23}$

$$
\mathbf{S}_{\mathbf{k}, \mathrm{i}}^{\text {nas }}=\frac{\hat{\mathbf{x}}_{\mathbf{A}, \mathbf{k}}^{\text {nas }}}{\mathrm{y}_{\mathrm{i}}}
$$

where the vector of sensitivities $S_{k}^{\text {nas }}$ must be the same for all calibration samples, $\hat{\mathrm{X}}_{\mathrm{A}, \mathrm{k}}^{\mathrm{nas}}$ is the vector for the net analyte signal for the $\mathrm{k}$ analyte and $\mathrm{y}_{\mathrm{i}}$ is the reference value of the sample $i$. The sensitivity can be estimated as:

$$
\mathrm{SE \hat {N }}=\left\|\mathbf{s}_{\mathbf{k}}^{\text {nas }}\right\|
$$

Analytical Sensitivity defined as the ratio between the sensitivity and the instrumental noise:

$$
y=\frac{S \hat{E} N}{\|\delta x\|}
$$

The inverse of this parameter $\left(\gamma^{1}\right)$ reports the minimum concentration difference between two samples that can be determined by the model. ${ }^{24}$

Selectivity in univariate calibration, selectivity is defined as the extent to which the method can be used to determine particular analytes in mixtures or matrices without interferences from other components with similar behavior. ${ }^{24}$ Otherwise, in multivariate calibration with the use of NAS, it is calculated as a ratio of the scalar nas and the Euclidean norm of the original vector of the instrumental responses $\mathbf{x}_{\mathrm{k}, \mathrm{un}} \cdot{ }^{21}$

$S \hat{E} L_{k, u n}=\frac{n a ̂ S_{k, u n}}{\left\|x_{k, u n}\right\|}$

SÊL indicates the portion of the instrumental signal that is used for the multivariate calibration model.

Confidence Intervals defined as the range within which it is possible to assume, with a given degree of confidence (it, a certain probability), that the true value of the concentration of the analyte of interest is included. It can be determined by a t-test and an approximate estimate for the variance of the prediction error $(\mathrm{V}(\mathrm{PE}))$. The $\mathrm{V}(\mathrm{PE})$ can be determined by the Errors in Variables (EIV) theory, ${ }^{25}$ that under simplifications reduces to the equation adopted in ASTM E1655-00,,$^{20}$ expressed as:

$\mathrm{V}(\mathrm{PE})=\left(1+\mathrm{h}_{\mathrm{un}}+\frac{1}{\mathrm{n}}\right) \mathrm{MSEC}$ where MSEC is the mean squared error of calibration and $\mathrm{h}_{\mathrm{un}}$ is a leverage for the prediction sample, defined as: ${ }^{18,20}$

$\mathrm{h}_{\mathrm{un}, \mathrm{A}}=\mathbf{t}_{\mathrm{un}}^{\top}\left(\mathbf{T}_{\mathrm{A}} \mathbf{T}_{\mathrm{A}}^{\top}\right) \mathbf{t}_{\mathrm{un}, \mathrm{A}}$

where $\mathbf{T}_{\mathrm{A}}$ is the score matrix of the calibration samples and $\mathbf{t}_{\mathrm{un}, \mathrm{A}}$ the score of an unknown sample. The number of degrees of freedom used in the calculation of MSEC is determined by the approach of pseudo degrees of freedom proposed by Van Der Voet. ${ }^{26}$

After V(PE) calculation of confidence intervals (f) can be obtained by:

$\phi= \pm t \sqrt{\mathrm{V}(\mathrm{PE})}$

where $t$ is the statistical parameter of the $t$-Student distribution.

Bias according to the IUPAC definition, ${ }^{23}$ bias is the difference between the population mean and the true value. Systematic errors are all error components that are not random. Then, it is possible to equate systematic errors with the fixed bias of the chemical measurement process. The occurrence of systematic errors was investigated by a $t$-test described in the ASTM E1655-00. ${ }^{20}$ First, an average bias is calculated for the validation set:

bias $=\frac{\sum_{i=1}^{\operatorname{lv}}\left(y_{i}-\hat{y}_{i}\right)}{\operatorname{lv}}$

where lv is the number of samples in the validation set. Then the standard deviation of validation (SDV) is obtained by:

$\operatorname{SDV}=\sqrt{\frac{\sum\left[\left(\mathrm{y}_{\mathrm{i}}-\hat{\mathrm{y}}_{\mathrm{i}}\right)-\mathrm{bias}\right]^{2}}{\operatorname{lv}-1}}$

Finally, the $\mathrm{t}$ value is given by:

$t_{\text {bias }}=\frac{\mid \text { bias } \mid \sqrt{I V}}{S D V}$

If the $\mathrm{t}$ calculated is greater than the critical $\mathrm{t}$ value at the $95 \%$ confidence level, there is an evidence that the bias included in the multivariate model is significant.

Goodness of fit the evaluation of this parameter is usually accomplished by a curve fitting of the prediction values versus the reference ones, calculation of the correlation coefficient, y-intercept and the slop of the regression line. ${ }^{18}$ Another way to do this evaluation is to use the net analyte signal calibration line, obtained by a

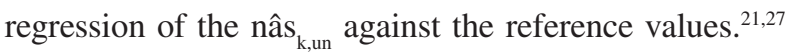


Linearity the evaluation of this figure of merit is problematic in multivariate calibration using PLS, because the variables are previously decomposed by principal component analysis. The plot of residuals and scores versus the reference values is a qualitative estimate of the linearity of the model, where they must present random and linear behaviours, respectively. However, the score plot only can be used when the PLS model requires a few latent variables to describe the data set. ${ }^{18}$

Limit of Detection ( $L O D$ ) following the IUPAC recommendations, the $\mathrm{LOD}$ can be defined as the minimum detectable value of net signal (or concentration) for which the probabilities of false negatives $(\beta)$ and false positives $(\alpha)$ are $0.05 .{ }^{23}$ The LOD can be calculated analogously as for univariate calibration: ${ }^{28-30}$

$L O D=3 \delta x\left\|b_{k}\right\|=3 \delta x \frac{1}{S \hat{E N N}}$

Limit of Quantification ( $L O Q$ ) the ability of quantification is generally expressed in terms of the signal or analyte concentration value that will produce estimates having a specified relative standard deviation. ${ }^{23}$ Following the same assumptions described above, the LOQ in multivariate calibration has been calculated by: ${ }^{28}$

$L O Q=10 \delta x\left\|b_{k}\right\|=10 \delta x \frac{1}{S E \hat{N}}$

\section{Results and Discussion}

The calibration set was optimized by outlier elimination, based on data with extreme leverage ${ }^{18}$ in calibration, unmodelled residuals in spectral data ${ }^{20}$ and unmodelled residuals in concentration (property of interest). ${ }^{18}$ The outliers in validation set were determinated by estimation of the extreme leverage and unmodelled residuals in spectral data. This procedures resulted in 897 , 924 and 857 calibration samples and 362, 358 and 368 validation samples for BRIX, POL and RS, respectively.

The optimum model dimension was determined by the minimum RMSECV (Root Mean Squares Error of Cross Validation) for the calibration samples, obtained by contiguos block cross validation of 10 samples. Four, six and four PLS factors for BRIX, POL and RS, respectively, were necessary to retain a significant variance in the data and to avoid a significant bias in the model. The presence of relevant bias was tested with the prediction results for the validation samples by the $t$-test suggested by ASTM E1655-00. ${ }^{20}$ The results showed that the bias included in the model was not significant, since the $t$ values obtained 2.07, 1.37 and 2.17 for BRIX, POL and RS, respectively, were lower that the critical value of 2.576 with $99 \%$ of confidence.

Results for the figures of merit are presented in the Table 1. Accuracy values represented by RMSEC (Root Mean Square Error of Calibration) and RMSEP (Root Mean Square Error of Prediction) showed that the estimated values of all multivariate models presented good agreement with reference methods.

Precision, at level of repeatability, was assessed by analysis of three samples with six replicates each, in measurements made in the same day. The results for BRIX and POL showed that the multivariate models were better than the regulated norms of evaluation of the quality of the cane sugar that is $0.3 \%$ for BRIX and $0.6 \%$ for POL. For RS, feasible results were also observed, but there is no regulated norm for precision of this parameter, since in industry it is not determined experimentally but just estimated by an equation that takes in consideration the BRIX and POL parameters. ${ }^{2}$ However, the value of RS is important for grower payment in the industry.

For sensitivity and analytical sensitivity good results were observed for the three parameters studied, taking into account the analytical range of the models. Analytical sensitivity is simpler and more informative for comparison and to judge the sensitivity of an analytical method. It is possible to establish a minimum concentration difference which, in the absence of errors in the property of interest, is discernible by the analytical method in the range where it was applied. Based on this result, for BRIX it is possible to distinguish between samples with value differences of around $0.22 \times 10^{-2} \% /$ juice.

Results for signal-noise ratio showed in Table 1 are the maximum values observed for each parameter. These values, apparently low, did not present a direct relation with the prediction errors. A feasible explanation for these results is that the estimates of the instrumental noise $(\delta \mathrm{x})$ do not represent the whole data set. This result suggests that the estimated LD and LQ presented in Table 1 might be optimistic values.

Figures 2, 3 and 4, show the goodness of fit of the models for BRIX, POL and RS, respectively. The slope, intercept and correlation coeficient for the models are also shown in Table 1. Models for BRIX and POL presented a similar fit that is clearly better than the one observed for RS. Inferior fit for RS might be explained due the presence of errors in the reference values. Unfortunately, in this work, it was not possible to estimate these errors. Another possibility for the inferior fit is a non-linear behavior in the relation between the NIR spectra and the concentration of reducing sugars. 
Table 1. Analytical figures of merit for the calibration model

\begin{tabular}{|c|c|c|c|c|c|}
\hline & Figures of merit & & BRIX & POL & RS \\
\hline \multirow{10}{*}{ Accuracy ${ }^{\mathrm{a}}$} & & RMSEC & 0.30 & 0.44 & 0.28 \\
\hline & & RMSEP & 0.28 & 0.42 & 0.26 \\
\hline & Precision $^{\mathrm{a}}$ & & 0.02 & 0.08 & 0.08 \\
\hline & Sensitivity ${ }^{\mathrm{b}}$ & & 0.06 & 0.02 & 0.32 \\
\hline & Analytical Sensitivity ${ }^{a}$ & & $0.22 \times 10^{-2}$ & $0.87 \times 10^{-2}$ & $0.23 \times 10^{-3}$ \\
\hline & Selectivity & & 0.30 & $9.56 \times 10^{-2}$ & 0.27 \\
\hline & Signal-noise Ratio & & $6.69 \times 10^{3}$ & $2.18 \times 10^{3}$ & $6.05 \times 10^{3}$ \\
\hline & Goodness of fit & Slope & $0.99 \pm 0.01$ & $0.99 \pm 0.01$ & $0.76 \pm 0.01$ \\
\hline & Intercept & & $0.18 \pm 0.06$ & $0.23 \pm 0.02$ & $0.19 \pm 0.01$ \\
\hline & Corr. Coef.(R²) & & 0.99 & 0.99 & 0.76 \\
\hline \multirow[t]{5}{*}{ Goodness of fit NAS } & & Slope & $15.00 \pm 0.06$ & $56.00 \pm 4.51$ & $2.90 \pm 0.05$ \\
\hline & & Intercept & $8.90 \pm 0.04$ & $4.40 \pm 1.01$ & $-0.21 \pm 0.02$ \\
\hline & Corr. Coef.(R²) & & 0.99 & 0.99 & 0.81 \\
\hline & Limit of Detection ${ }^{\mathrm{a}}$ & & $0.69 \times 10^{-2}$ & $2.62 \times 10^{-2}$ & $0.13 \times 10^{-2}$ \\
\hline & Limit of Quantification ${ }^{\mathrm{a}}$ & & 0.02 & 0.09 & $0.44 \times 10^{-2}$ \\
\hline
\end{tabular}

${ }^{a}$ Results in $\%$ of juice and ${ }^{\mathrm{b}} \%$ of juice ${ }^{-1}$.

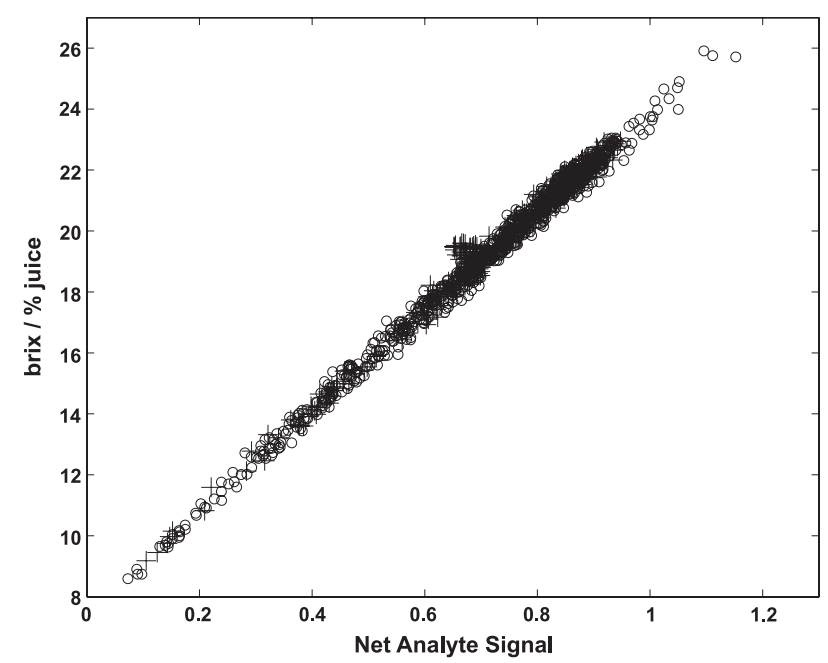

Figure 2. Plot of NAS versus references values for BRIX. Calibration (o) and Validation (+) samples.

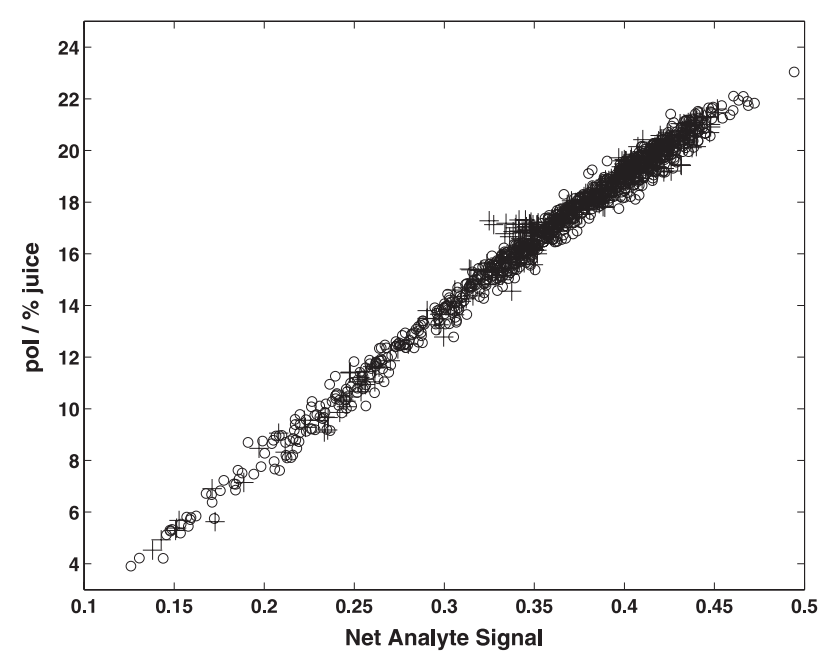

Figure 3. Plot of NAS versus references values for POL. Calibration (o) and Validation (+) samples.

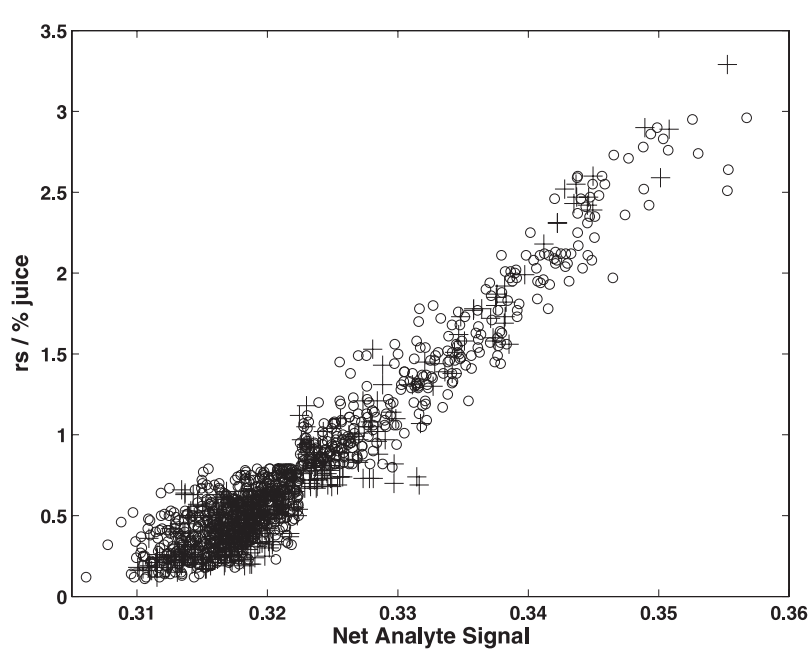

Figure 4. Plot of NAS versus references values for RS. Calibration (o) and Validation (+) samples.

The error distribution for BRIX and POL parameters presented a random behavior, while for the RS parameter it a tendency (bias) was observed that reinforces the suspicion of non-linearity in the data set. Figures 5, 6 and 7 show the histograms for the student residuals for BRIX, POL and RS. These distributions resemble a gaussian behavior, but by using a Jarque-Bera test ${ }^{31}$ only for BRIX the student residuals are normally distributed while for POL and RS significant differences from normality were observed. The CL values, estimated at $95 \%$ of probability by equation 16 , demonstrated a level of coverage near the nominal values, since the results for BRIX, POL and RS were: 96.9; 95.8 and 95.6, respectively. This good agreement confirms the concordance of the estimate of uncertainties given by equation 14 for all properties and the observed prediction errors, despite the distribution of the residuals observed for POL and RS. For each sample a specific CL is obtained, and the mean CL 


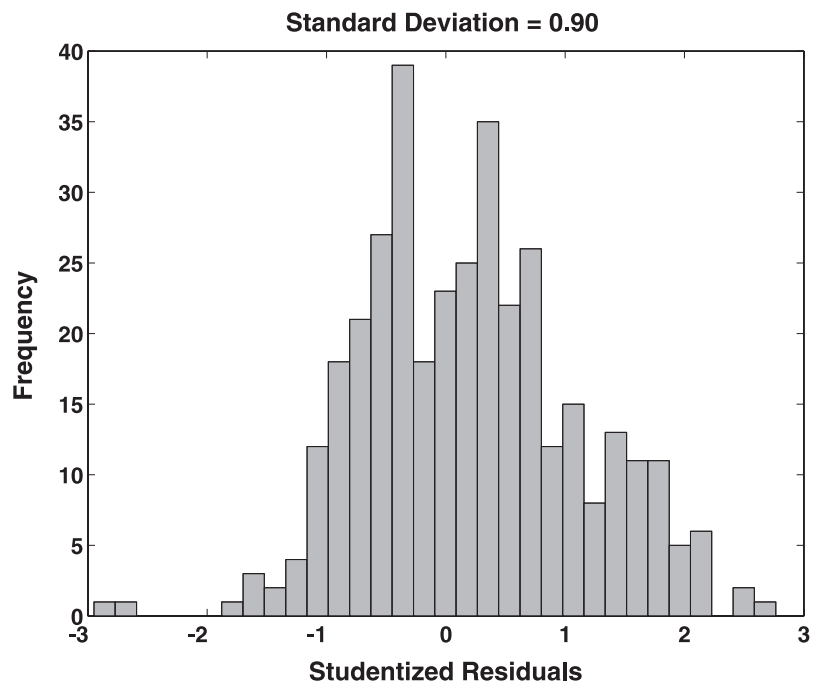

Figure 5. Histogram of the Student Residuals for BRIX.

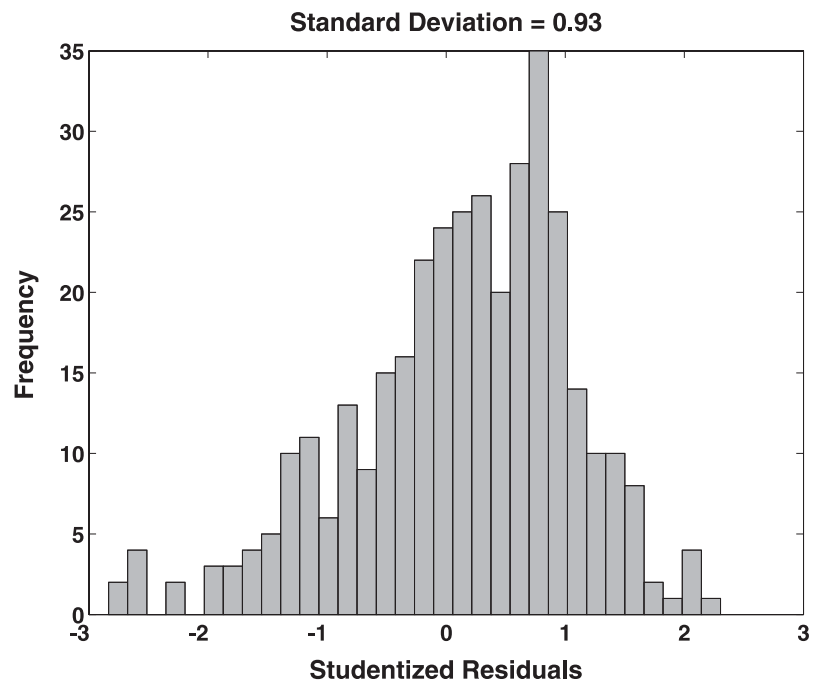

Figure 6. Histogram of the Student Residuals for POL.

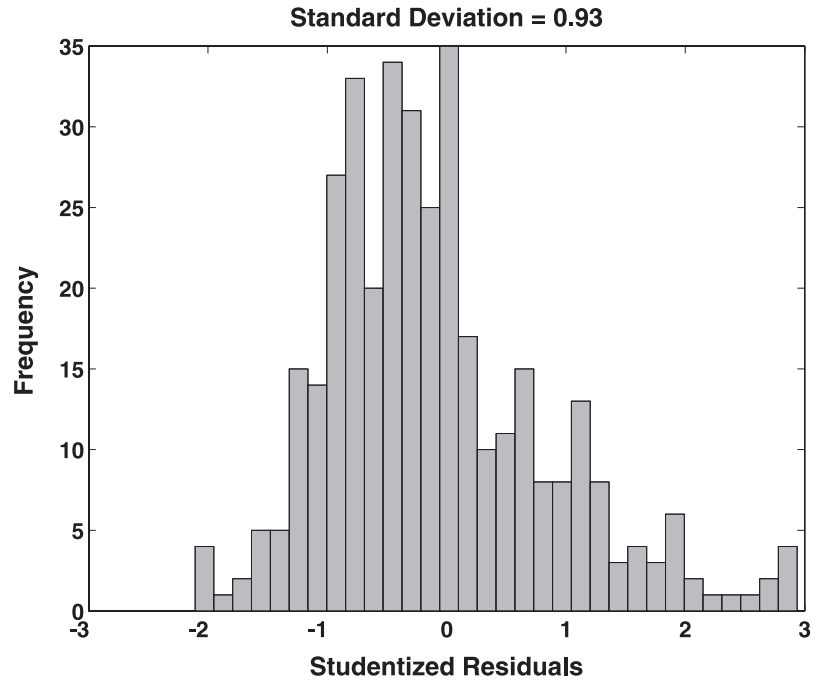

Figure 7. Histogram of the Student Residuals for RS. obtained for BRIX, POL and RS were $\pm 0.60, \pm 0.87$ and \pm 0.54 , respectively. These results show that for BRIX and POL there are acceptable uncertainties compatible with the analytical range of the calibration models. Otherwise, for RS parameter, the CL calculated is incompatible with the concentration range studied, indicating that the proposed methodology based on NIR is not suitable for this parameter determination.

\section{Conclusions}

Determinations of BRIX, POL and RS were accessed by PLS models based on NIR spectroscopy. The models were built and validated using a representative set of samples obtaining feasible and acceptable results. The prediction errors obtained for BRIX and POL were lower than claimed at regulated norm. Confidence limits determined at the $95 \%$ confidence level for prediction samples, showed a good agreement with the expected probability of coverage. The models showed a large sensitivity capacity, differentiating samples with a low difference of concentrations. The values for accuracy, precision and other figures of merit presented promising results, indicating that the model developed by near infrared spectroscopy for BRIX and POL can be used in the sugar cane industry as an alternative to refractometry and polarization measurements (standard methods for BRIX and POL, respectively). The NIR-PLS procedure present the advantage of simpler sample preparation, since is not required that the samples of cane juice have been cleared with lead sub-acetate. Other advantages are simultaneous determination of BRIX and POL with the same NIR spectra and the possibility for on-line monitoring. For RS, using the oxidation-reduction titration method as a reference, the results of the NIR method present a better agreement than the values from the industrial equation. Therefore, the NIR method can be indicated for RS estimate in the industry, however, it should be approved for the official regulatory agency.

\section{Acknowledgments}

The authors thank COCAMAR - Cooperativa Agroindustrial for allowing the development of the experimental set-up of this work in its industrial unit. We also thank to CAPES and UNICAMP for financial support.

\section{References}

1. Shreve, R. N.; Brink Jr, J. A.; Chemical Process Industries, Mcgraw-Hill International: Auckland Bogota, 1977.

2. Payne, J. H.; Unit Operations in Cane Sugar Production, Elsevier Science Pub. Co: Amsterdam, 1982. 
3. Conselho dos produtores de cana-de-açúcar, açúcar e álcool do estado do Paraná: CONSECANA-PR; Normas Operacionais de Avaliação da Qualidade da cana-de-açúcar, FAEP Federação da Agricultura do Estado do Paraná: Curitiba, 2000. Site (URL): http://www.faep.com.br/consecana/normasop.htm, accessed in January 2004.

4. George, P. M.; Cane Sugar Handbook: A Manual for Canesugar Manufacturers and their Chemists, John Wiley \& Sons Inc.: New York, London, Sydney, 1963.

5. Cadet, F.; Bertrand, D.; Robert, P.; Maillot, J.; Dieudonné, J.; Rouch, C.; Appl. Spectrosc. 1991, 45, 166.

6. Cadet, F.; Robert, C.; Offmann, B.; Appl. Spectrosc. 1997, 51, 369.

7. Baunsgaard, D.; Norgaard, L.; Godshall, M. A.; J. Agric. Food Chem. 2000, 48, 4955.

8. Johnson, T. P.; Intern. Sugar J. 2000, 102, 603.

9. Irudayaraj, J.; Xu, F.; Tewari, J.; J. Food Sci. 2003, 68, 2040.

10. Sivakesava, S.; Irudayaraj, J.; J. Food Sci. 2001, 66, 972.

11. Tewari, J.; Mehrotra, R.; Irudayaraj, J.; J. Near Infrared Spectrosc. 2003, 11, 351.

12. Costa Filho, P. A.; Poppi, R. J.; Proceedings of the $9^{\text {th }}$ International Conference on Near Infrared Spectroscopy, Verona, Itália, 1999.

13. Salgo, A.; Nagy, J.; Mikó, É.; J. Near Infrared Spectrosc. 1998, 6, A101.

14. Kennard, R. W.; Stone, L. A.; Technom. 1969, 11, 137.

15. Burns, D. A.; Ciurczak, E. W.; Handbook of Near-Infrared Analysis, Marcel Dekker: New York, 2001.

16. Goicoechea, H. C.; Olivieri, A. C.; Chemom. Intell. Lab. Syst. 2001, 56, 73.
17. Faber, N. M.; J. Chemom. 1998, 12, 405.

18. Martens, H.; Naes, T.; Multivariate Calibration, Wiley: New York, 1989.

19. Faber, K.; Kowalski, B. R.; Appl. Spectrosc. 1997, 51, 660.

20. Annual Book of ASTM Standards, Standard Practices for Infrared Multivariate Quantitative Analysis - E1655-00, ASTM International, West Conshohocken: Pennsylvania, USA, 2000.

21. Lorber, A.; Faber, K.; Kowalski, B. R.; Anal. Chem. 1997, 69 , 1620.

22. Ferré, J.; Brown, S. D.; Rius, F. X.; J. Chemom. 2001,15, 537.

23. Currie, L. A.; Anal. Chim. Acta. 1999, 391, 105.

24. De la Pena, A. M.; Mansilla, A. E.; Valenzuela, M. I. A.; Goicoechea, H. C.; Olivieri, A. C.; Anal. Chim. Acta. 2002, $463,75$.

25. Faber, K.; Kowalski, B. R.; J. Chemom. 1997, 11, 181.

26. Van Der Voet, H.; J. Chemom. 1999, 13, 195.

27. Braga, J. W. B.; Poppi, R. J.; J. Pharm. Sci. 2004, 93, 2124.

28. Boqué, R.; Rius, F. X.; Chemom. Intell. Lab. Syst. 1996, 32, 11.

29. Boqué, R.; Larrechi, M. S.; Rius, F. X.; Chemom. Intell. Lab. Syst. 1999, 45, 397.

30. Boqué, R.; Faber, N. M.; Rius, F. X.; Anal. Chim. Acta. 2000, $423,41$.

31. Jarque, C. M.; Bera, A. K.; Int. Stat. Rev. 1987, 55, 163.

Received: May 31, 2006

Web Release Date: February 5, 2007

FAPESP helped in meeting the publication costs of this article. 